\title{
ON THE EPISTEMOLOGICAL SIGNIFICANCE OF VALUE PERCEPTION
}

\author{
Michael Milona
}

\section{$0 \quad$ Introduction}

A recent flurry of articles and books defend the possibility of value perception, with a guiding thought being that the question of whether there is value perception is of significant import to value epistemology. ${ }^{1}$ I examine this thought. Most of the paper focuses on what I call the high-level theory of value perception, an increasingly popular theory (or, rather, family of theories). At a first pass, a high-level theory says that at least some ordinary perceptual experiences - whereby 'ordinary' denotes the traditional five-senses - can in certain instances have veridical evaluative content. ${ }^{2}$ (We'll see below why this is called 'high-level'.) My central claim is that value epistemologists needn't take sides in difficult debates about high-level value perception; it just isn't an important epistemological question. ${ }^{3}$ But I close the paper by noting that it may matter

\footnotetext{
${ }^{1}$ For a sampling, see John Greco Putting Skeptics in Their Place: The Nature of Skeptical Arguments and Their Role in Philosophical Inquiry (New York: Cambridge University Press, 2000); Mark Johnston, 'The Authority of Affect', Philosophy and Phenomenological Research 61.1 (2001), 181 - 214; Graham Oddie, Value, Reality, and Desire (New York: Oxford University Press, 2005); Sabine Döring, 'Seeing What to Do: Affective Perception and Rational Motivation', Dialectica (2007), 363 - 394; Sergio Tenenbaum, Appearances of the Good: An Essay on the Nature of Practical Reason (New York: Cambridge University Press, 2007); Timothy Chappell, 'Moral Perception', Philosophy 83 (2008), 421 437; Robert Audi, 'Moral Perception and Moral Knowledge', Proceedings of the Aristotelian Society Supplementary Volume 84 (2010), 79 - 97; Robert Audi, Moral Perception (Princeton, NJ: Princeton University Press, 2013); Andrew Cullison, 'Moral Perception', European Journal of Philosophy 18.2 (2009), 159 - 175; Justin McBrayer, 'A Limited Defense of Moral Perception', Philosophical Studies 149 (2010), 305 - 320, 291 - 307; Justin McBrayer, 'Moral Perception and the Causal Objection', Ratio 23.3 (2010), 291 - 307; Jennifer Church, 'Seeing Reasons', Philosophy and Phenomenological Research 85.3 (2010), 638 - 670; Jennifer Church, Possibilities of Perception (Oxford: Oxford University Press, 2013); Robert Roberts, Emotions in the Moral Life (New York: Cambridge University Press, 2013); and Preston Werner, 'Moral Perception and the Contents of Experience', Journal of Moral Philosophy (2014), 1 - 24.

${ }^{2}$ The reader will notice that I regularly shift between 'perception' and 'perceptual experience'. The former, of course, is factive; I can only perceive that $\mathrm{p}$ if it really is the case that $\mathrm{p}$. There can thus only be value perception if there are values. In this paper, I simply assume there are. More specifically, I assume that if there are value perceptual experiences, then there are value perceptions. One who disagrees can substitute 'perceptual experience' for any instance of 'perception'.

${ }^{3}$ Numerous philosophers hold that high-level value perception is possible. My dispute is not with the view itself but, rather, with its significance for value epistemology. (For a different way of attacking the import of high-level value perception, see Robert Cowan 'Perceptual Intuitionism', Philosophy and Phenomenological Research 90.1 (2015), 164 193.) For a sampling of works that not only defend high-level value perception but also assume that the debate about high-level value perception matters for value epistemology, see John Greco, op. cit. note 1; Audi, op. cit. note 1, 'Moral Perception and Moral Knowledge'; Audi, op. cit. note 1, Moral perception; Cullison, op. cit. note 1; McBrayer, op. cit. note 1, 'A Limited Defense of Moral Perception' and McBrayer, op. cit. note 1, 'Moral Perception and the Causal Objection'. Matters are a bit complicated when it comes to Cullison, however (see section 4).
} 
a great deal whether a certain other picture of value perception is true. ${ }^{4}$ This alternative picture has it that desiderative and/or emotional experiences often involve perceptual experiences of value. $^{5}$

The paper begins by describing the notion of an ambitious theory of value perception, which plays an important dialectical role in my central argument. An ambitious theory says (roughly) that any justified belief about whether something is valuable (e.g., good, bad, right, wrong) epistemically depends on value perceptual experiences, whatever exactly those experiences are supposed to be. In the next two sections, I describe the high-level theory in more detail and then explain why it is not a plausible basis for an ambitious theory. But as I go on to note, it still appears to matter quite a bit for value epistemology whether there is such a thing as highlevel value perception. Appearances, however, are misleading. Reflection on how one of the alternative ways of justifying evaluative beliefs - a way that the defender of high-level value perception in particular needs to allow - relates to high-level value perception leads to the conclusion that the question of whether there is any high-level value perception is not so significant, after all.

\section{$1 \quad$ Ambitious Theories}

This section sketches the outlines of what I call an ambitious theory of value perception. The crucial point that I want to make is that even an ambitious theory should allow for some evaluative knowledge not grounded in value perception, namely what I call below non-substantive evaluative knowledge. Placing such a limitation not only helps to avoid certain objections, but is also natural for the theory. Let me explain.

\footnotetext{
${ }^{4}$ As far as I am concerned, a given theory counts as a theory of value perception if it posits either (i) literal value perceptions or (ii) value experiences that share with ordinary perceptual experiences the features that make ordinary perception such a good way to acquire knowledge. Defenders of the high-level view defend the existence of literal value perceptions.

${ }^{5}$ Defenses of this view include Dennis Stampe, 'The Authority of Desire', The Philosophical Review 96.3 (1987), 335 381; Roberts, op. cit. note 1; Oddie, op. cit. note 1; and Döring, op. cit. note 1.
} 
Some philosophers have argued that theories of value perception cannot explain the full range of evaluative knowledge. ${ }^{6}$ Consider the following remark from Simon Blackburn ${ }^{7}$ :

Literal talk of perception runs into many problems. One is that the ethical very commonly, and given its function in guiding choice, even typically, concerns imagined or described situations, not perceived ones. We reach ethical verdicts about the behavior of described agents or actions in the light of general standards. And it is stretching things to see these general standards as perceptually formed or maintained. Do I see that ingratitude is base only on occasions when I see an example of ingratitude? How can I be sure of the generalization to examples that I did not see (I could not do that for color, for instance. Absent pillar-boxes may be a different color from present ones; only an inductive step allows us to guess at whether they are). Or, do I see the timeless connection-but how? Do I have an antenna for detecting timeless property-to-value connections? ${ }^{8}$

There is a lot going on in this quote, but I simply want to highlight the thought that a perceptual view can't be squared with our knowledge of supervenience. ${ }^{9}$ Blackburn is baffled by how we could ever (literally) perceive a supervenience relation. Do we generalize from cases, or do we

\footnotetext{
${ }^{6}$ Pekka Väyrynen suggests that defenders of perceptual views often seem to commit themselves to the bold claim that all of our evaluative knowledge is grounded in value perception, or at least the claim that no ethical knowledge is a priori. See Pekka Väyrynen, 'Some Good and Bad News for Ethical Intuitionism', The Philosophical Quarterly 58.232 (2008), 495 - 96. Many of the "Cornell Realists", for instance, seem to suggest that all of our evaluative knowledge is acquired by observation, in a way analogous to how we acquire knowledge in science. See especially Richard Boyd in 'How to Be a Moral Realist', in Essays on Moral Realism. ed. Geoffrey Sayre-McCord (Ithaca, NY: Cornell University Press, 1988. 181 - 228). I won't engage in the lengthy exegetical task to try to pin the bold view on these thinkers, however.

${ }^{7}$ For a similar sentiment (although about a different theory of value perception not of immediate concern here), see Michael Smith, The Moral Problem (Malden, MA: Blackwell, 1994), 22.

${ }^{8}$ Simon Blackburn, 'How to Be an Ethical Antirealist', Midwest Studies in Philosophy 12 (1988), 364 - 65. After listing these questions which he takes to indicate problems for the target theories, Blackburn says, 'Perhaps these questions can be brushed aside' (ibid, 365). I'll point out in a moment that they clearly can be. That said, my best guess is that Blackburn is lead to pose these 'challenging' questions because defenders of value perception often seem to be defending the view that all of our evaluative knowledge can be grounded in value perceptions.

${ }^{9}$ I believe that Blackburn is referring to a supervenience relation when he talks about 'timeless connections', but if he really means to refer just to a temporal relation then my point in this section could be reframed accordingly.
} 
(as Blackburn mockingly suggests) have an antenna for detecting eternal property-to-value connections?

The response should just be that perception is not the basis for our knowledge of the supervenience of evaluative properties on non-evaluative properties, which seems to be a nonsubstantive, or conceptual, evaluative truth. ${ }^{10}$ Another candidate example of a non-substantive true is the transitivity of value: if $\mathrm{x}$ is better than $\mathrm{y}$, and $\mathrm{y}$ is better than $z$, then $\mathrm{x}$ is better than $z$. It is presumably acceptable to have different standards for answering different kinds of questions. Blackburn himself makes this point. For Blackburn, a truth is conceptual just in case 'we cannot imagine it otherwise; we could make nothing of a way of thought which denied it'. ${ }^{11}$ But in both ethical and non-ethical domains, it may turn out that some truths aren't conceptual, and so must be discovered by other means. Blackburn tells us:

In particular in the moral case it seems conceptually or logically necessary that if two things share a total basis of natural properties, then they have the same moral qualities. But it does not seem a matter of conceptual or logical necessity that any given total natural state of a thing gives it some particular moral quality. For to tell which moral quality results from a given natural state means using standards whose correctness cannot be shown by conceptual means alone. It means moralizing... ${ }^{12}$

So some ethical questions can be settled by conceptual standards alone, while others need to be settled by other standards. Blackburn places an unreasonable constraint on the ethicist who has

\footnotetext{
${ }^{10}$ Some philosophers argue that conceptual truths can be substantive. See Terence Cuneo and Russ Schafer-Landau, 'The Moral Fixed Points: New Directions for Moral Nonnaturalism', Philosophical Studies 171.3 (2014), 399 - 443. Although I think it is a mistake to allow for non-substantive conceptual truths, nothing important turns on this disagreement here. However, allowing substantive conceptual truths leaves less room for value perception to play an important role, unless we allow that value perception helps us to learn conceptual truths.

${ }^{11}$ See op. cit. note 8, 217. Alternative ways of characterizing conceptual knowledge are available, and I won't try to adjudicate between them here. See, for instance, Paul Boghossian, 'Analyticity Reconsidered', Nous 30 (1996), 360 391.

${ }^{12}$ Simon Blackburn, Spreading the Word: Groundings in the Philosophy of Language. (New York: Oxford University Press, 1984), 184.
} 
value perception playing a central role in value epistemology; we would never place an analogous constraint on paradigmatic forms of perception, as if visual perception couldn't play a central role in acquiring empirical knowledge unless it informed us of certain conceptual truths. ${ }^{13}$

I propose, then, that we can usefully define an ambitious theory of value perception as a theory that accepts the following: for any value property, $\mathrm{V}$, perceptions of value are epistemically indispensable for knowing that something (an object, way of acting, particular action, etc.) is $\mathrm{V}$, assuming the something in question is not $\mathrm{V}$ by definition. ${ }^{14,15}$ A natural thought for a defender of this ambitious view to have is that without value perceptions, we wouldn't have any input to begin to form justified (substantive) ethical beliefs, for even if there were valuable things, nothing would seem good or bad, right or wrong. For such an ambitious theorist, even the question of whether an agent's perceptual faculties are working well is probably going to be a question for value perception, unless one believes such a question can be answered conceptually. ${ }^{16}$

\section{High-Level Value Perception}

An ambitious theory of value perception would be of great interest, since it would provide an answer to the question of how we know substantive truths about value; a question with relevance not only to the epistemology of value but also the metaphysics of value. After all, if we can find no plausible account for how we know about value properties, this is a step toward calling into question whether there really are any. An unambitious theory may still be interesting, of course;

\footnotetext{
${ }^{13}$ That said, as I mention above (note 8), Blackburn remarks at the end of his list of challenging questions that the defender of value perception may be able to set the questions aside. Blackburn may think his questions are only a problem if his targets accept a very bold thesis about the extent of our evaluative knowledge that value perception can explain. The text is unclear on this point.

${ }^{14} \mathrm{I}$ do not require that the perceptual experiences be of an object's being $\mathrm{V}$. An ambitious theorist can allow that we need value experiences to know about the presence of any value (goodness, badness, rightness, etc.), even though we only have perceptual experiences of certain values. Suppose, for instance, that we can perceive goodness but not rightness. If the concept of rightness is analyzed in terms of that of goodness, then value perceptions may still be essential for knowing what is right, even though we never perceptually experience anything as being right. See my 'Taking the Perceptual Analogy Seriously', Ethical Theory and Moral Practice (forthcoming).

${ }^{15}$ Testimony, for instance, is plausibly a way of justifying evaluative beliefs, too, but testimony is not plausibly an epistemically independent route. Robert Cowan offers a helpful definition of epistemic dependence: 'a state, d, epistemically depends on another state, e, with respect to content $\mathrm{c}$ iff e must be justified or justification conferring in order for d to be justified or justification-conferring with respect to content c' (op. cit. note 3, 2).

${ }^{16}$ But this is not a bad result, for maters are much the same with ordinary perception. We can only learn when our perceptual faculties are function well by relying on perception. For more on this, see Milona op. cit. note 14.
} 
but even if an unambitious theory were defensible, we would still be left with the task of defending some other account (or accounts) of what grounds the other substantive evaluative knowledge that we have. And, furthermore, there may also be a desire for a unified theory of what grounds such knowledge, in which case an ambitious theory would be a desideratum (though perhaps one we could eventually be talked out of). Before we can consider whether any theory of value perception can be ambitious, however, we need to know more about the theories on offer. For this paper, I focus on high-level value perception, which in recent years has been growing in popularity. This section explains what a high-level theory of value perception is. The ensuing sections explain why such theories not only fail to be ambitious but fail to be interesting at all.

It's uncontroversial that familiar types of perceptual experience can have low-level content. I take the content of any perceptual experience to be the accuracy conditions of an experience that are conveyed (or presented) to the subject. ${ }^{17}$ For example, a visual experience as of a red sailboat in the distance is accurate just in case there is a red sailboat in the distance; and the phenomenal character of the visual experience consists (at least partly) in those accuracy conditions appearing to the observer to be the case (i.e., being conveyed to her). Low-level visual content includes (inter alia) color and shape. (Or, in the case of audition, low-level content includes pitch and tone. But to keep things simple, I'll stick with vision.)

While some theorists contend we can only perceive such low-level content, others are drawn to more liberal views. ${ }^{18}$ At the least, we often talk as if we can perceive other things. For example, we often speak of seeing that there is an apple, that one event caused another, etc. Following Nicholas Silins, I define high-level (visual) perception as perception with content other than shape, color, and location (low-level content). ${ }^{19}$ The defender of high-level perception

\footnotetext{
${ }^{17}$ On this way of thinking about content, see Susanna Siegel, The Contents of Visual Experience (New York: Oxford University Press, 2011), 28.

${ }^{18}$ Those who reject the possibility of any high-level perception include Fred Dretske in Naturalizing the Mind (New York: Cambridge University Press, 1995) and Austin Clarke in A Theory of Sentience (New York: Oxford University Press, 2000).

${ }^{19}$ See Nicholas Silins, 'The Significance of High-Level Content', Philosophical Studies 161.1 (2013), 13 - 33. One might worry about such a definition by list. The reason for defining low-level content in this way is, at least in part, to denote the problem-space in a theory-neutral way. More illuminating definitions often arise after further theorizing.
} 
claims that some ordinary perceptual experiences can have high-level content. The defender of high-level value perception defends this claim for values, in particular. Finally, I use the words 'ordinary' and 'familiar' to denote the traditional five-senses, i.e., vision, audition, gustation, tactility, and olfaction. The high-level view, as I discuss it, is a view about (at least some of) those familiar sense modalities. ${ }^{20}$ If we drop 'ordinary' from the definition of high-level value perception, then in our discussion of theories of value perception, we risk collapsing the distinction between importantly different kinds of views. ${ }^{21}$

The plan for getting a better handle on what high-level theories of value perception essentially are is by way of considering an exemplar of such a view. Robert Audi (in his recent Moral Perception), as I interpret him, develops the most detailed account of high-level value perception of which I'm aware, and so the aim is to take advantage of his extensive treatment of the topic to help in getting a handle on the target view. ${ }^{22}$ The criticisms I develop in the ensuing sections turn not on any idiosyncrasies of Audi's position but, instead, only on the features that make his view, or any view, a high-level theory of value perception.

To begin, Audi points out that a thought inimical to the possibility of value perception is the thought that all visual perception has to be cartographic. Cartographic perception involves a "mapping" from phenomenal properties (low level properties like shape and color) to

See, for example, Alva Noë, 'Conscious Reference', The Philosophical Quarterly 59.236 (2009), 470-82; and Cowan, op. cit. note 3 .

${ }^{20}$ If we allow for such high-level perceptual content, then there will plausibly be cases in which our experiences in one sense-modality affect our experiences in another modality. My auditory experiences may affect what I see, e.g., I see that a person as saying such-and-such, and that experience is intimately related somehow to my auditory experience of the sounds of the speech. In any case, for this paper, I do not try to answer whether or not such experiences are irreducibly intermodal. Nothing important for my arguments turns on the possibility of intermodal experiences. For more discussion on these issues, see Siegel, op. cit. note 17, 24 - 26.

${ }^{21}$ If we define the high-level theory of value perception as the theory that we can have perceptual experiences with evaluative content, then we risk counting the theory that emotions have evaluative content as a theory of high-level value perception. But the view that emotions are perceptual experiences that can have evaluative content is prima facie very different from the view that some visual experiences can have evaluative content.

${ }^{22}$ Some read Audi as defending a view of value perception which is subtly different from the high-level view. See Pekka Väyrynen, 'Doubts about Moral Perception', this volume. For reasons which will become clear below, however, I resist this reading (see especially note 31 ). But in any case, we should not get bogged down by interpretative questions, for the view that I interpret Audi as defending is held by numerous philosophers, including, among others, McBrayer op. cit. note 1, 'A Limited Defense of Moral Perception'; Cullison op. cit. note 1; and Werner op. cit. note 1. 
properties perceived. ${ }^{23}$ Audi's example of cartographic perception involves going from the impression of four squares to the property of being divided into four squares. It isn't plausible that value perception can work on a cartographic model, since there is no mapping of phenomenal properties to evaluative properties. But Audi at least, believes that this mapmaking idea of perception is undermotivated and does not square-well with the phenomenology of actual perception. ${ }^{24}$ We seem to have non-doxastic visual experiences of properties that we cannot easily have arrived at in a way consistent with the cartographic model. ${ }^{25}$ For example, when a trained botanist and a lay person walk through a forest together, it is natural to expect that the surroundings will look different to the botanist, for her expertise would seem to help her to see the different kinds of foliage. ${ }^{26}$

If there is such a thing as visual value perception, then there must be "phenomenal sensings' of wrongdoing/badness/goodness/etc., since for anything we see (e.g., a lemon) there is something it is like to see it. ${ }^{27}$ To get a grip on what it might be like to see value, consider an example. A patron in a bar is casually watching a married couple. ${ }^{28}$ The husband is quite intoxicated, yet he nonetheless requests another whisky. His wife kindly asks him to stop drinking, and he responds by slapping her across the face. The observer can see the wrong act, but can he see its wrongness? Well, Audi finds that the observer's perception of the wrongmaking features may be coupled with a distinctive kind of phenomenology, which we would naturally describe as a recognition (not necessarily involving any belief) of wrongdoing; this

\footnotetext{
${ }^{23}$ Audi, op. cit. note 1, Moral Perception, $37-8$

${ }^{24}$ See Audi, ibid, 38 - 9.

${ }^{25}$ I find much of what Audi says about the cartographic model to be underdeveloped. It perhaps would have been useful for him to appeal to Susanna Siegel's much discussed "phenomenal contrast" argument for why we should believe visual experiences with high-level contents are possible. Siegel uses the argument specifically to argue we can perceive natural kinds, but a parallel argument could be developed, I think, for values. (It has recently come to my attention that Werner, op. cit. note 1, tries to do just this.) Siegel's argument, like Audi's, appeals to phenomenology, but it is a far more robust abductive argument that attempts to head off alternative explanations of the phenomenological data. See Siegel, op. cit. note 17.

${ }^{26}$ An opponent of high-level perception will want to try to explain the different way in which the botanist and lay person experience their surroundings without appealing to differences in how things look. Susanna Siegel, op. cit. note 17, argues in much more detail than Audi against many of these alternative explanations (although Siegel does not consider value perception, in particular), but for our purposes, we need not go into so much detail.

${ }^{27}$ Sometimes philosophers say, which comes to the same thing, that all perception is experiential.

${ }^{28}$ This example is from Audi, op. cit. note 1, Moral Perception, 61 - 2.
} 
phenomena is plausibly a phenomenal sensing of wrongdoing, exactly what we're after. ${ }^{29}$ This is a kind of 'felt connection' between the base (wrong-making) properties and the property of being wrong. Audi's claim is that the relationship ('felt connection') between the ordinary perception (of the wrong-making features) and the phenomenal sensing of an evaluative property is such that it is correct to speak of value perception. Speaking of a sensing of injustice, in particular, Audi says:

The sense of injustice, then, a kind of impression of it, one might say, as based on, and as phenomenally integrated with, a suitable ordinary perception of the properties on which injustice is consequential-grounded, to use another term for the same relation-might serve as the experiential element in moral perception.

An important constituent in this phenomenal integration is the perceiver's felt sense of connection between, on the one hand, the impression of, say, injustice or (on the positive side) beneficence and, on the other hand, the properties that ground the moral phenomena. ${ }^{30}$

As I interpret Audi, it's best to separate his view into two key commitments: (i) there are a variety of different kinds of phenomenal sensings of evaluative properties, which can apparently occur independently of value perception (see section 5), and (ii) the content of these phenomenal sensings is often integrated into the content (i.e., the accuracy conditions conveyed to the subject in her experience) of familiar perceptual experiences so as to generate a value perception. ${ }^{31}$

\footnotetext{
${ }^{29}$ It is helpful to notice that high-level value perception is probably going to be one of the most controversial forms of high-level perception. This is because it depends on our ability to have high-level perceptual experiences of the properties (e.g., persons, mental states, causes) that (metaphysically) ground the values.

${ }^{30}$ Audi, ibid, 38 - 9

${ }^{31}$ Audi isn't explicit that by 'integration' he means integration into the content. But I think this is what he intends, and it is, in any case, hard to see how he can avoid it. Consider that Audi thinks that we can literally see wrongness. But then if he doesn't think the phenomenal representation of wrongness is part of the content of the visual experience, then it seems he'd have to think a visual experience as of something's being wrong could be correct (assuming a visual experience is correct just in case its content is true) even if there's no wrongness, because the wrongness isn't part of the content. But then it's hard to see how talk of seeing wrongness could be anything other than metaphorical, contrary to what Audi says. Furthermore, if by 'integration' Audi doesn't mean integration into the content, then his
} 
It is a delicate task to characterize in greater detail how Audi understands 'what it is like' to experience an evaluative property. If I understand the view correctly, phenomenal sensings of evaluative properties are manifold; in fact, phenomenal sensings of the same evaluative properties can vary. Audi tells us that felt sense of connection may be partly constituted by an emotion, though it need not be. ${ }^{32}$ (So we should not take the word feel' to necessarily indicate an emotional experience.) It may also be partly constituted by an intuition. ${ }^{33}$ Audi tries to capture the rich variety of phenomenal sensings by engaging in phenomenological inquiry, drawing distinctions on the basis of an examination of different cases. ${ }^{34}$ For instance, in one case, we may "feel" disapproval when a man deliberately spills hot liquid on his friend's hand. Or there may be a 'felt unfittingness between the deed and the context, as where we see a male and female treated unequally in a distribution of bonuses for the same work'. ${ }^{35}$ But experiences of unfittingness can happen in different ways; it can be conceptual, as it often is with an adult who sees that an act is unjust, or can be non-conceptual, as it may be with a young child who is uncomfortable at seeing peers treated unequally. ${ }^{36}$ More could be said about how Audi analyzes various different types of phenomenal sensings, but this basic characterization of Audi's highlevel theory of value perception is sufficient for my purposes.

Generally speaking, I understand any high-level view to be committed to both a phenomenological thesis and an integration thesis. ${ }^{37}$ The first step is to identify certain evaluative

view may actually be interpretable as a counter-hypothesis to the common way of formulating the thesis that there is high-level value perception. On this last point, see Robert Cowan, 'Review of Robert Audi's Moral Perception', Mind $123.492,1167-1171$.

32 See Audi, op. cit. note 1, Moral Perception, 39.

${ }^{33}$ See Audi, ibid, 134 - 36. For Audi, intuitions can come in a variety of forms. We can have an intuition that $p$, which is a kind of belief. We can also have objectual intuitions, which are direct apprehensions of concepts, properties, or relations (see ibid, 85 - 88). Both kinds of intuitions can presumably constitute phenomenal sensings of an evaluative perception. Though, as far as I can tell, Audi only mentions the possibility that an intuition that $\mathrm{p}$ can be part of an evaluative perception.

${ }^{34}$ After identifying the different ways we can have a phenomenal sensing of an evaluative property, he goes on to sketch theoretical accounts of each of those ways. It would be tangential to my purposes to spell all this out in detail.

${ }^{35}$ Audi, ibid, 39 - 40

${ }^{36}$ See Audi, ibid, 45 - 49.

${ }^{37}$ Cowan, op. cit. note 3, mentions (but then sets aside) the possibility of a view on which humans are 'hard-wired' for visual value perception, a view which would apparently not require the integration thesis. I consider this importantly different (though rarely defended) kind of view in my 'Intellect vs. Affect: Finding Leverage in an Old Debate' (unpublished). 
experiences (I'll often follow Audi in speaking of sensing value properties) and the second is to argue that the content of the experiences can be integrated into the content of familiar kinds of perceptual experiences to produce a value perception. (Integration secures the possibility of literal visual, auditory, etc. experiences of evaluative properties; the high-level view isn't the far more familiar and less controversial view that we can have evaluative responses to visual, auditory, etc. experiences but that are external to the visual, auditory, etc. experience's content.)

\section{The Need for an Alternative Way}

Defenders of high-level value perception claim that the perception of values is tied to one or more of the ordinary five senses. ${ }^{38}$ (Audi discusses visual, tactile, and auditory value perception.) In the case of vision, we see high-level properties by seeing other, low-level properties. This means that in imagining a scenario, an agent will never literally see any values, for she is not having a visual experience. ${ }^{39}$ The following thesis seems rather obviously true:

Limits: In imagining something, we do not perceive it with any of our five-senses.

Of course, it's almost surely true that our ability to reflect, whether imaginatively or not, causally depends on our having certain experiences. (Even mathematical reflection likely depends on having some experiences.) But the point is that the ordinary senses aren't part of what constitutes such reflection. ${ }^{40}$

There are manifold ways in which we engage the imagination in evaluative reflection. The paradigm is when sensorily imagine various sights, sounds, smells, etc. For example, in reflecting on the moral status of torture, we may conjure up images of the sights and sounds of

\footnotetext{
${ }^{38}$ I assume defenders of the high-level view don't believe that there is any other kind of value perception. But they actually could; the view that desires and/or emotions often involve perceptions of values is compatible with the highlevel view. At certain points, Audi seems to suggest that emotions can be a kind of value experience (perhaps similar in some ways to perceptual experience) contained within a visual experience, making that visual experience evaluative. ${ }^{39}$ As Audi points out, visual imagination is 'possible even given blindness'. And so 'It is not perceptual' (ibid, 9).

${ }^{40}$ For helpful discussion on the relationship of experience to ethical and mathematical reasoning, see Sarah McGrath, 'Moral Knowledge and Experience', in Oxford Studies in Metaethics: Volume 6. ed. Russ Schafer-Landau. (New York: Oxford University Press, 2011. 107 - 127).
} 
a suffering prisoner. ${ }^{41}$ In other cases, we imagine in a way that does not seem to be straightforwardly sensory, if even sensory at all. ${ }^{42}$ Most obvious here are the cases when we imagine content that is not perceivable, e.g., that Athens wins the Peloponnesian War or that McCain wins the 2008 U.S. election. ${ }^{43}$

The crucial point for us is that the imagination, whether sensory or not, can sometimes be a route to evaluative knowledge, and this is a problem for any high-levelist who advocates what I have labeled an ambitious theory of value perception (at least insofar as she thinks high-level value perception is the only kind of value perception that there is). Much of ethical inquiry is deliberation about what to do in the future; and when we engage in such reflection, there is nothing yet to perceive, at least in so far as our five senses are concerned. ${ }^{44}$ Although one could hold that substantive evaluative knowledge or justification for beliefs about what is valuable can only be acquired through high-level value perception, and not by, say, imaginatively simulating how events would unfold if we performed a given action, such a view seems difficult to motivate on theory-independent grounds. ${ }^{45}$

One intuitive way to push this thought is to notice an apparently important asymmetry between evaluative and empirical inquiry. While with the latter we rely on actual experiments,

\footnotetext{
${ }^{41}$ There is a great deal of complexity that I am glossing over here. For example, in visually imagining a suffering prisoner, we might imagine having a visual experience of the suffering or simply imagine it from some viewpoint. On this distinction, see, for instance, Richard Wollheim, Painting as an Art (Princeton, NJ: Princeton University Press, 1987); and Dominic Gregory, 'Imagery, the Imagination and Experience', The Philosophical Quarterly 60.241 (2010), $735-753$.

${ }^{42}$ I think it is a mistake to suppose that the imagination is essentially sensory. But if one thinks it is, then I am happy to call the phenomena I am about to describe 'reflection'. Nothing turns on the disagreement.

${ }^{43}$ See Stephen Yablo, 'Is Conceivability a Guide to Possibility?', Philosophy and Phenomenological Research 53 (1993), 1 42; and M. Oreste Fiocco, 'Conceivability, Imagination, and Modal Knowledge', Philosophy and Phenomenological Research 74.2 (2007), 364 - 380.

${ }^{44}$ Dancy makes this point, but he seems to have in mind value perception as such. See Jonathan Dancy 'Moral Perception', Proceedings of the Aristotelian Society Supplementary Volume 84 (2010), 115 - 116. In my view, his claim is correct if we're considering a high-level view of value perception, but it may be overstated if we are talking about desiderative or emotional evaluative perception (see section 6).

${ }^{45}$ Richard Swinburne articulates the core idea as follows: "When examples of particular situations (e.g., the trolley problem) are adduced in order to persuade us that some general moral principle is or is not true, it is quite irrelevant whether the examples are examples of an actual event or of an imagined event. What matters is what it would be right to conclude about which actions in that situation would be good or bad; whether or not the situation actually occurred is irrelevant'. See Swinburne's 'Necessary Moral Principles', Journal of the American Philosophical Association 1.4 (2015), 620 .
} 
evaluative inquiry only seems to require thought experiments. ${ }^{46}$ It is one thing to deny that any of our evaluative beliefs count as knowledge, or (less plausibly) that they are ever justified; it is another thing altogether to deny the following premise: if ordinary deliberators can gain evaluative knowledge through high-level value perception (e.g., that her helping the man across the street is good), then in most cases, they could have gained similar evaluative knowledge through imagining (e.g., that her helping the man across the street would be good). A theory which denies the possibility of evaluative knowledge by mere reflection is going to be highly revisionary; and many would rightly count such a commitment as a serious strike against the theory.

We can push the point a bit more with an example. Consider a toddler who has never had any high-level perceptual experiences of wrongness. To be sure, this toddler has perceptually experienced things which are wrong (e.g., lying), but she has never perceptually experienced anything as wrong. Now imagine our toddler cackling to herself as she remembers, say, pushing another toddler into the mud. But after a moment or two of imagining the scenario, as her attention is drawn in a special way to her peer's pain and embarrassment, she suddenly experiences her act as wrong. It seems to me that the high-levelist should allow that this is perfectly possible, and that this experience is a source of justification similar to as if she had actually visually experienced the wrongness. The high-levelist should allow that we can acquire justification for an evaluative belief through imagining some possibility; and that justification will in many cases be independent from any evaluative perceptions.

The following thesis is difficult to deny:

Liberality: Justification for evaluative beliefs can be gained, independently of highlevel value perceptual experiences, by imaginatively reflecting (whether sensorily or non-sensorily) on cases. ${ }^{47}$

\footnotetext{
${ }^{46}$ McGrath, op. cit. note 40, makes this point.

${ }^{47}$ For the central argument of this paper, it is only important that we can gain evaluative justification independently of high-level value perception by way of either the sensory imagination or non-sensory imagination. It is not required that we be able to acquire evaluative justification in both ways. But because our ability to acquire knowledge in both
} 
Liberality is silent about the exact way in which we acquire evaluative justification through the imagination, and, more specifically, what high-levelists should say about this. But if what I have argued in this section is correct, we can at least say that high-level value perception is not an attractive basis for an ambitious theory of value perception. (And it will become even clearer in the next section why that is.) The next section defends a much stronger claim: building off Limits and Liberality, I claim that so long as we accept a few more attractive theses, whether there is high-level value perception is simply not an important issue at all for value epistemologists.

\section{$4 \quad$ High-Level Value Perception and Imagination}

\subsection{Isn't It Obvious?}

The argument in the previous section hardly shows that the question of whether there is highlevel value perception is not important for value epistemology. A natural thought is that if we discover that there are such perceptions, we will have discovered a unique and distinctive way in which we can acquire evaluative knowledge. Consider why we might care about any brand of high-level perception, whether evaluative or otherwise. ${ }^{48}$ Many philosophers are inclined to believe that our perceptions can give us immediate (basic or non-inferential) justification for relevant beliefs. Such philosophers have tended to focus on the perception of low-level properties like color and shape, assuming that other things, e.g., kinds, causation, emotion, are outside the reach of perception. To account for our knowledge of such phenomena, one has to explain how we can rationally transition from our immediately justified perceptual beliefs to our beliefs about kinds, causation, emotions, etc. However, if we can literally perceive such things, then perhaps one can argue with some plausibility that the range of immediately justified beliefs

\footnotetext{
ways becomes relevant when we consider a revised version of the high-level view (section 5), I simply work with the strong principle for the sake of simplicity.

${ }^{48}$ My discussion in this paragraph of why we might care about high-level value perception is inspired by Nicholas Silins's recent discussion of the potential significance of high-level perception more generally (op. cit. note 19). I say 'inspired' because his discussion is far more detailed and subtle than I can reproduce here. (Silins ultimately has his own reasons for wanting to temper excitement about high-level perception in general.)
} 
is much greater than initially realized. This observation might lead us to think that whether there is high-level value perception is of deep importance to value epistemology. But that would be a mistake. My claim is that the defender of high-level value perception should adopt three theses that jointly (along with Limits and Liberality) mute the epistemological significance of whether there is high-level value perception.

\subsection{Normative Similarity}

I noted in the previous section that a defender of high-level value perception should allow that, in addition to acquiring (substantive) evaluative justification through perception, we can also acquire it through imaginative reflection (Liberality). I suggest that the defender of high-level value perception should probably accept a further normative similarity between imagination and value perception:

Normative Similarity: Imaginative reflection can in principle (though perhaps with one exception to be explained below) supply just as good evidential support for a normative belief that something would be good/bad/wrong/etc. as any value perception of the relevant evaluative property can supply for the belief that the relevant thing is good/bad/wrong/etc.

Just as the patron in the bar can literally see that the husband behaves badly when he slaps his wife, he could also see "in the mind's eye" that such behavior would be bad. And, of course, seeing "in the mind's eye" is not literally seeing; it doesn't actually engage the visual faculties and so isn't a high-level perception. But the rational support for the belief would apparently be the same. When we engage in imaginative reflection, we do not ordinarily think that we need to actually observe the case to be sure that the verdict about the imaginary case is correct. We don't think we need to use perception as a 'check' on our value judgments about hypothetical cases. ${ }^{49}$

\footnotetext{
${ }^{49}$ Dancy, op. cit. note 44, makes an observation along these lines.
} 
In the statement of Normative Similarity, I noted that we may want to complicate the principle by allowing for an exception. Here's the candidate exception:

Normative Similarity-Exception: the "vividness" of a value perceptual experience is often revelatory of something's evaluative significance in a way that cannot be replicated imaginatively, at least not by ordinary human agents.

Consider a person, Cindy, who imagines killing her rival, Lenny. When she imagines what it would be like, killing him appears very good, especially given all the awful things Lenny has done. Now suppose she carries out the act by driving a knife through Lenny's heart. After carving into Lenny's chest, well past the point of no return, the killing starts to appear differently. The apparent disvalue of her act intensifies as she sees Lenny wriggling on the floor, gasping for his last few breaths. Because the action is now presented to her in a more "vivid" way, she is able to see the badness of her act. Perhaps the vividness of this experience could never (for a human being, at least) be fully replicated imaginatively. The term 'vividness' may be interpreted in different ways. It might have to do, for instance, with our inability to accurately imagine in full detail what it would be like to actually experience something. Or, it might have to do with the greater reliability (at least sometimes) of our evaluative responses to actually perceived scenarios. So maybe value perception is in many cases better for revealing degrees of value (due to the "vividness" of perception). For my purposes, I'll assume that value perception is, at least in some cases, superior to imagination for revealing degrees of value. (However, merely imagining a possibility, as opposed to actually experiencing it, occasionally provides us with the "reflective distance" needed to make a soberer and more accurate evaluative judgment. This will especially be the case when we do not enjoy doing what is best or right.) But as I will endeavor to show, we should doubt that there is any plausible way of filling in what 'vividness' means that salvages the epistemological significance of high-level value perception.

As we'll see over the next two sub-sections, granting a certain descriptive similarity between imagination and high-level value perception means that Normative Similarity-Exception can't salvage the significance of the question of whether there's high-level value perception. This 
descriptive similarity helps to drive home the epistemological inconsequence of high-level value perception. ${ }^{50}$

\subsection{Descriptive Similarity}

Audi emphasizes the parallels between value perception and moral imagination. ${ }^{51}$ He says:

$[T]$ he exercise of moral imagination can, through vivid imaging of morally significant events, and through envisaging diverse possibilities, produce an experience significantly like a moral perception. ${ }^{52}$

This claim isn't surprising. Our imaginations allow us "replay" and "preplay" perceptual experiences; the different components of the perceptual experience will have analogues that are 'in the mind's eye. ${ }^{53}$ In some cases, those "analogues" turn out to be the very same kinds of phenomena involved in actual experiences. Intuitions (of whatever kind, if one believes, like Audi, that there are many kinds) had in response to actual cases are plausibly the same kind of thing as intuitions had in response to imaginary ones. Likewise for the emotions. Recall now the notion of sensing (or experiencing) an evaluative property, which is necessary for the possibility of high-level value perception. (High-level value perception involves the integration of one of these sensings with a suitable ordinary perceptual experience.) For any sensing of an evaluative property involved in value perception, there will be an analogue of that sensing that could have occurred had the agent imagined the same scenario. But should we go further, claiming that the sensings had in response to imaginative cases are the very same kinds of phenomena? To make the question vivid, return to the case of the husband who wrongfully slaps his wife when she asks him not to have another whisky. As we saw, the observer's perception of wrongness (assuming he does see the wrongness) is partly constituted by a sensing

\footnotetext{
${ }^{50}$ One can also read the next section as providing further support for Normative Similarity.

${ }^{51}$ Ethical imagination is not a special type of imagination; it's just imagining about ethical matters.

${ }^{52}$ Audi, op. cit. note 1, Moral Perception, 160

${ }^{53}$ See Audi, ibid, 47
} 
of wrongdoing. But had the observer imagined the case, rather than perceived it, could he have had the same kind of experience (sensing) of wrongdoing? ${ }^{54}$ I claim the following:

Descriptive Similarity: For any sensing of an evaluative property suitably integrated with an ordinary perception to create a value perception, the same kind of sensing of an evaluative property could occur through imagining such a case.

If Descriptive Similarity is true, then it can help us see why Normative Similarity seems correct. This is because in both perceptual and imaginary cases, it's plausibly the sensings that are doing the important justificatory work (see also section 4.4 below). But why think Descriptive Similarity is true?

As I have already suggested, there are phenomenological grounds for believing this thesis. To begin, consider emotions and intuitions. Just as we can experience an emotion, say, revulsion, at some actual event, we can experience revulsion when reading fiction or the newspaper, imagining possibilities, etc. Furthermore, the same kind of intuitive response might be had to a given scenario, whether actual or possible. Part of the reason such claims about emotions and intuitions go mostly unquestioned in the literature is, I believe, because denying them would fly in the face of actual experience..$^{55}$ My view is that matters are much the same with sensings of evaluative properties. Audi assumes without much ado that the myriad of ways we can sense an evaluative property have analogues in imagination, I am going one step beyond: the reason this seems obvious is that the very same kinds of experiences can occur when we consider imaginary cases. ${ }^{56}$ Although I'm open to counterexamples, I can't conceive any way of

\footnotetext{
${ }^{54}$ Of course, we should be careful about generalizing from one case, but I think matters will be much the same for other examples.

${ }^{55}$ Some philosophers do claim that emotions had in response to fictions and some imaginings are different in type. See Kendall Walton 'Fearing Fictions', The Journal of Philosophy 75 (1978), 5 - 27; and Tyler Doggett and Andy Egan, 'How We Feel About Terrible, Non-Existent Mafiosi', Philosophy and Phenomenological Research 84.2 (2012), 277 - 306. But the reasons why they believe this do not provide an attractive model for resisting Descriptive Similarity (see note 57 below).

${ }^{56}$ But notice that the analogue claim may be enough for the main point. Suppose the experiences are different, e.g., in virtue of different functional roles. Well, even if that's defensible, it may still be that what is epistemically significant about the sensings remains constant in responses to imagined cases and actual ones. In that case, I would simply have to rephrase Descriptive Similarity to be about that feature rather than the sensings.
} 
sensing of an evaluative property that cannot be reproduced in imagination. ${ }^{57}$ And if I've got the phenomenology correct, that's outstanding evidence for Descriptive Similarity, since after all, sensings of evaluative properties just are certain kinds of experiences.

In sum, from a phenomenological angle, it seems Audi should allow that what's distinctive about value perception is never the sensing of the evaluative property, as such, which could occur in merely imagining the same case. What's special about high-level value perception is the sensing's integration with the ordinary perceptual experience (see section 2 ), which secures the possibility of seeing, hearing, etc. values.

\subsection{Immediacy}

Descriptive Similarity and Liberality (the claim that imagination is a source of justification for evaluative beliefs) make it highly attractive to adopt one last thesis:

Immediacy: the various sensings of evaluative properties are sources of immediate justification for relevant evaluative beliefs, whether in response to real or imagined cases.

To deny this claim, while accepting each of Descriptive Similarity and Liberality would generate a peculiar asymmetry in the way our evaluative beliefs are justified. ${ }^{58}$ It isn't clear what could warrant positing the asymmetry, and I suspect positing such an asymmetry would seem unattractive to a defender of high-level value perception.

To get a grip on Immediacy, a bit more needs to be said about what sorts of evaluative beliefs are justified by our responses to imaginings. Consider a concrete case. Sandra and

\footnotetext{
57 There is a complication worth flagging. As I mentioned in note 55, some philosophers (e.g., Walton, op. cit. note 55; and Doggett and Egan, op. cit. note 55) believe that emotions in response to (some) imaginings and fictions really are different in type. But the best case for this counterintuitive view appeals to the apparently different functional and motivational profiles of our offline responses. This doesn't provide a model for resisting Descriptive Similarity, at least not in a way that matters. For one, it is not clear that we should be typing phenomenal sensings by their motivational profiles. And, furthermore, even if we do, an "online" sensing and its "offline" analogue will still be the same in that they present the same evaluative properties or relations; and it is that psychological constant which matters.

${ }^{58}$ As far as I'm aware, those who argue that high-level value perceptions are important in moral epistemology hold that value perceptions are in standard cases sources of immediate justification for relevant evaluative beliefs.
} 
Ronaldo are enjoying themselves at a party, until Ronaldo suddenly, and unexpectedly, finds himself embroiled in an uncomfortable conversation about his political beliefs. Sandra, who isn't directly involved in the conversation, is looking for a way to diffuse the situation. Sandra quickly imagines several possible courses of action: (i) stepping in to defend Ronaldo's views, (ii) telling Ronaldo's questioner to pipe down, since Ronaldo is uncomfortable, or (iii) subtly trying to change the subject by bringing up an interesting but apolitical news story. She imagines events unfolding in different ways, depending on the course of action she has in mind. Her evaluative responses to the different imaginings give her some immediate justification for an evaluative belief about the possibility as she imagines it. ${ }^{59}$ As it turns out, when Sandra imagines subtly changing the subject (and the subsequent unfolding of events), she experiences that choice and subsequent unfolding of events (however she imagines those things as unfolding) as especially good. She has non-immediate justification for believing that right now it would be good to attempt to subtly change the conversation insofar as she is justified in believing that her situation is similar (in non-normative respects), and would unfold in similar ways, to the situation she just imagined. There is much more that would need to be said to give a complete account of how we get justification for evaluative beliefs through imaginative reflection, but these brief remarks should suffice to illustrate the only point needed for my purposes: the high-levelist should allow that evaluative experiences had in response to imagined scenarios supply us with immediate justification for relevant evaluative beliefs.

\subsection{Summing Things $U p$}

We're now in a position to recognize why accepting the three theses I've put forward makes the question of whether there is high-level value perception unimportant for value epistemology. If the defender of high-level value perception accepts each thesis, then she's committed to the

\footnotetext{
${ }^{59}$ Our evaluative responses to imaginings that are vague and undetailed will presumably not be a particularly good source of justification for evaluative beliefs, although the high-levelist should allow that even in those cases, we get some justification. Similarly, we may have high-level value perceptual experiences on the basis of very limited information. Imagine a high-level visual experience as of S's taking money out of the wallet's being wrong. Well, if for all the agent knows the wallet is S's, then this experience won't be a great source of justification for believing S acts wrongly, even though it presumably provides some evidence (which is sure to be defeated).
} 
following: whether or not sensings of value are ever suitably integrated with ordinary perception to generate a high-level value perception, those sensings (or experiences) of value are already a source of immediate justification that is just as good. And, furthermore, although Normative Significance-Exception seemed to leave open the possibility that value perception is a crucially important way of gaining insight about something's degree of value, this isn't so. The myriad of ways in which we might sense value are already equipped to supply the same insights, whether or not they are integrated with an ordinary perception. To illustrate, return to Cindy's murder of Lenny. Consider Cindy imagining murdering Lenny. As her imagination of the deed becomes more vivid, she is poised to gain more insight into the degrees of the act's disvalue. But actually carrying out the act, and so seeing, hearing, and feeling it, supplies her with maximal vividness, which for ordinary humans is only going to be achievable by observing the actual deed. The actual experience may make possible greater insight, but the possibility of the greater insight is not dependent on the phenomenon of high-level value perception; it's made possible by the degree of vividness with which the bad-making properties are presented (in imagination or perception).

Defenders of the high-level view are forced to defend difficult, controversial theses in the philosophy of perception. It's very important, for example, that all visual perception isn't "cartographic," it's very important that it be possible for sensings of values to be suitably integrated with ordinary perceptions, and so on. High-level value perception, moreover, is plausibly going to be one of the most controversial kinds of high-level perception, since it typically depends on our ability to perceive the properties that ground the value properties. For instance, value properties are in some cases partly grounded in natural kind properties, but even the latest arguments for natural kind perception have been called into doubt. ${ }^{60}$ However important this debate about high-level value perception might be for understanding perception, it isn't important for value epistemology. Whether or not the sensings of values are ever "suitably integrated" with ordinary perceptions, the high-level theorist should already think such experiences are a source of justification that needn't itself be justified. ${ }^{61}$

\footnotetext{
${ }^{60}$ See Berit Brogaard. 'Do We Perceive Natural Kind Properties?', Philosophical Studies 162 (2013), 35 - 42.

${ }^{61}$ One might try to salvage the epistemological significance of high-level value perception as follows. It's a common thought that in order to imagine, say, colors, shapes, flavors, sounds, etc. we must first actually perceive those colors,
} 
Four points of clarification. First, I concede that value perception may be a common way in which we come to have evaluative knowledge. What I have claimed is that the defender of high-level value perception should accept certain theses that ensure any knowledge or justification we get by value perception is in an important sense also had on non-perceptual grounds (since integration is not doing epistemological work). And this mutes the epistemological significance of whether there is value perception. Furthermore, there are questions closely related to the question of whether there is high-level value perception that are clearly important for value epistemology, but we should distinguish the significance of such questions from the question of high-level value perception. For example, some philosophers may want to claim that evaluative perception isn't possible unless value properties are causally networked, or are reducible to properties that are. And the question of causation is hugely important in value epistemology (and metaethics as a whole). ${ }^{62}$ But it's causation that's important, strictly speaking, not perception. ${ }^{63}$

Third, I am not arguing that the question of whether there perceptual knowledge of value is insignificant, at least given a liberal understanding of what can count as perceptual knowledge. To illustrate, Andrew Cullison argues for high-level value perception as a way of securing perceptual evaluative knowledge. ${ }^{64}$ But when considering a certain objection to high-level value perception, he argues we may be able to get perceptual knowledge of value without high-level

\footnotetext{
shapes, flavors, sounds, etc. So one might argue that in order to be able to imaginatively experience value properties, we first have to perceptually experience those properties. In that way, the ability to perceptually acquire substantive evaluative knowledge is fundamental. (Audi may be making this claim about the fundamentality of value perception. See Audi, op. cit. note 1, Moral Perception, 173.) But if this is what the high-levelist needs to argue to salvage the significance of her view, then she has a serious argumentative burden, for the empirical claim about what is required for us to be able to imaginatively experience values needs defense. For example, we need to know why the case of values is like color rather than like, say, mathematics. While humans might need perceptual experiences of some kind to be able to engage in mathematical thinking, there's no need to invoke mathematical perceptual knowledge or experiences to explain how we're able to justify mathematical beliefs (see McGrath, op. cit. note 40). Furthermore, we need to know why the phenomenal sensing of value's being integrated into the content of a familiar kind of perceptual experience is at all important.

${ }^{62}$ See Oddie, op. cit. note 1; and David Enoch, Taking Morality Seriously: A Defense of Robust Realism (New York: Oxford University Press, 2011).

${ }^{63}$ Most defenders of value perception claim that the question of value perception doesn't turn on whether values are causally networked. See Audi, op. cit. note 1, Moral Perception; and McBrayer, op. cit. note 1, 'Moral Perception and the Causal Objection'.

${ }^{64}$ Cullison speaks of 'moral perception' rather than 'value perception', but I take the difference to be merely terminological.
} 
evaluative perception. His thought is that by perceiving things regularly correlated with some value property, $\mathrm{V}$, perhaps we can know on that basis that $\mathrm{V}$ is instantiated. I suspect he would also say we need to have some epistemically significant evaluative response, or intuition, to what we perceive. ${ }^{65}$ But even if many philosophers would balk at calling knowledge acquired by such means perceptual, I suspect they would find the description of the view, at least in the very abstract way Cullison describes it, a familiar and not terribly implausible picture of how we acquire evaluative knowledge.

The final point of clarification is that, strictly speaking, the theses I offer are not necessary to generate the result that the question of high-level value perception doesn't matter for value epistemology. We get the desired (or undesired, depending on your perspective) result so long as one accepts that it does not matter whether the content of phenomenal sensings of value is ever integrated into the content of ordinary perceptual experiences. What the theses do is draw attention to our ability to acquire evaluative knowledge through the imagination, independently of familiar perceptual experiences (see Limits and Liberality), and then to draw our attention to the descriptive and epistemological similarities between the knowledge we get by imagining cases and the knowledge we get by perceiving actual cases (see Normative Similarity, Descriptive Similarity, and Immediacy). The theses help us to see why the integration thesis - a central component of high-level value perception - simply doesn't matter for value epistemology. But even if it turns out, say, that Descriptive Similarity is false, because value experiences integrated with ordinary perceptions somehow have a different nature from those not so integrated, the high-levelist who maintains the import of her view still has a serious challenge: explain the epistemological import of integration.

\section{$5 \quad$ A Revised High-Level View}

As we know, an essential component of the high-level view is a claim about integration: evaluative content can literally be part of the content of visual, auditory, and tactile experiences. I have been trying to argue that whether the content of value experiences is so integrated just isn't an

\footnotetext{
${ }^{65}$ Cullison, op. cit. note $1,17-19$
} 
epistemologically significant question. I have pushed this thought by appealing to our ability to acquire evaluative justification through the imagination. Suppose now that a high-levelist contends that when we imagine scenarios, we often (passively) imagine seeing, hearing, and feeling evaluative properties. So, for example, when I imagine Wesley copying answers off Jackie's test, I also (let's suppose) passively imagine seeing Wesley's action as wrong. ${ }^{66}$ The revised high-level view says this: high-level perceptual experiences of value occur when we have visual and other familiar perceptual experiences of value properties, or when we passively imagine having such experiences. ${ }^{67}$ Although when we imagine having such experiences, we are not having genuine perceptual experiences, the defender of the revised high-level view claims that they're on a par with literal high-level value experiences.

This revised high-level view doesn't secure the view's epistemological importance. The first point to notice is that if there are value experiences, or sensings, of the sort the high-levelist imagines, it is unlikely they are tied essentially to actual or imagined visual, auditory, and tactile modes. For example, suppose we read a newspaper story about a complicated but sketchy WallStreet business deal. It seems we can reflect on the various propositions comprising the story without conjuring any sensory-like images of the events taking place. Nevertheless, when engaging in such reflection, we might have a phenomenal experience as of the deal's being bad. Take another case. Suppose we imagine that John McCain defeats Obama in the 2008 U.S. presidential election. Even if we conjure some images into our head when we imagine such a scenario, it is not clear that those sensory images are of the imagined event, since it does not seem as if someone's winning an election is the kind of thing that can be perceived. ${ }^{68}$ Nevertheless, it seems that when we imagine McCain defeating Obama in 2008, we may well have a passive experience as of its being bad.

\footnotetext{
${ }^{66}$ It is important that the imagining be passive, or involuntary. If someone actively decides to imagine that they see some action as wrong, then it is hard to see how that experience could supply them with evidence of anything.

${ }^{67}$ Janet Levin pointed out to me the possibility of revising the high-level view in this way.

${ }^{68}$ See Yablo, op. cit. note 43; and Fiocco, op. cit. note 43.
} 
There is another kind of case worth mentioning. Even when we imaginatively visualize something, we may not (and I suspect we normally do not) imagine having a visual experience of it. Dominic Gregory has a helpful analogy for illustrating the point:

We naturally interpret photographs as showing how things looked. We usually treat them as merely displaying the layout of a past scene, as showing how things once looked from a viewpoint within a previous situation...But we can also treat the same photos as showing how things looked in the course of past visual sensations, that is, in the course of visual sensations which occurred at viewpoints in past scenes. (Photos are sometimes used in that way in recounting first-personal narratives in comics, for example. $)^{69}$

Gregory's view is that the same goes for visual images. A given visualization may be an imagining of how things looked from some viewpoint, or it may be an imagining of a visual sensation from that viewpoint. But when we visualize something in the former way and have an evaluative experience in response to the imagining, the response will not be imagined as integrated with any imagined visual experience, since ex hypothesi there is not any imagined visual experience. So, it seems to me a stretch to maintain that evaluative experiences are in some way bound to ordinary perceptual experiences or imaginings of ordinary perceptual experiences. The highlevelist should allow that while experiences of goodness, badness, rightness, wrongness, etc. can often be integrated into sensory experiences, or imagined sensory experiences, they could also occur independently.

Now we can see that the revised high-level theory does not salvage the view's import. When we have evaluative experiences detached from ordinary perceptual experiences (real or imagined), as the high-levelist should allow is possible, it would be dogmatic to insist that in such cases, the experiences are not a source of immediate justification for evaluative beliefs. There does not seem to be anything special about real or imagined evaluative experiences that occur in

\footnotetext{
${ }^{69}$ Gregory, op. cit. note 41,744
} 
visual, tactile, or auditory modes. (As another example, suppose that we sensorily imagine something but then as it fades, we are suddenly struck by the badness of what we just imagined. We do not imagine seeing/hearing/touching badness, but it is hard to see how a high-levelist can avoid allowing that the experience is a source of justification just the same.) But then this suggests that if we come to find out that the high-levelist is wrong, and value experiences (along with their evaluative content) are never integrated into sensory experience or imagined sensory experience, but can at best be responses to sensory experience or imagined sensory experience, then it hard to see how that finding could be of much epistemological import.

\section{Conclusion: A More Epistemologically Exciting Model of Value Perception?}

The high-level theory of value perception isn't the only kind of value perceptual theory on offer. An alternative theory says that desires and/or emotions involve perceptual (or perceptual-like) experiences of value. Although I haven't the space to discuss any such view in detail (and there are a variety), it's worth noticing that, in contrast with high-level value perception, I suspect it is a very interesting question for value epistemology whether desires and/or emotions are perceptual experiences of value. As noted above, we have desiderative and emotional responses not only to actual cases but also imaginative and fictional ones. For instance, when imagine a complicated business deal, or the possibility that McCain won the 2008 election, we may well have desiderative and emotional responses. Furthermore, as ethicists and psychologists alike have noticed, desires and emotions are ubiquitously present in human evaluative thought. ${ }^{70} \mathrm{~A}$ theory according to which emotions and desires are perceptual experiences of value can arguably explain why; it is because affective experiences are the way, or mode, by which we come to recognize evaluative properties, analogous to how visual experiences are the way we come to recognize colors. ${ }^{71}$

\footnotetext{
${ }^{70}$ For a sampling of the relevant psychological literature, see Shaun Nichols, Sentimental Rules; On the Natural Foundations of Moral Judgment (New York: Oxford University Press, 2004).

${ }^{71}$ For contemporary defense of this kind of view, see Oddie op. cit. note 1. Jessica Moss attributes such a view to Aristotle in Aristotle on the Apparent Good: Perception, Phantasia, Thought, and Desire (New York: Oxford University Press, 2012).
} 
ACKNOWLEDGMENTS: I would like to thank Greg Ackerman, Robert Cowan, Stephen Finlay, Janet Levin, Mark Schroeder, Ralph Wedgwood, and Preston Werner for incredibly helpful feedback on earlier drafts of this paper. Thanks also to audiences at the University of Glasgow and the University of Southern California. Finally, I benefitted significantly from conversations with Anna Bergqvist, Michael Lacewing, Fiona McPherson, Indrek Reiland, Susanna Siegel, and Pekka Väyrynen. 